TAO, Vol. 14, No. 3, 261-288, September 2003

\title{
Precipitation Simulation Associated with Typhoon Sinlaku (2002) in Taiwan Area Using the LAPS Diabatic Initialization for MM5
}

\author{
Guo-Ji Jian ${ }^{1, *}$, Shinn-Liang Shieh ${ }^{1}$, and John A. McGinley ${ }^{2}$
}

(Manuscript received 8 January 2003, in final form 7 May 2003)

\begin{abstract}
A precipitation simulation associated with Typhoon Sinlaku using the fifth-generation Pennsylvania State University - National Center for Atmospheric Research Mesoscale Model (MM5) initialized diabatically with the Local Analysis and Prediction System (LAPS) is evaluated over the Taiwan area. Two purposes of this paper are to test the performance of the LAPS diabatic data assimilation technique and investigate the impact of the Doppler radar data on the short-range quantitative precipitation forecasts for the typhoon. Typhoon Sinlaku was selected because Doppler radar is one of the most important data sources for an accurate analysis of typhoons and Sinlaku was located close to the Wu-Fen-Shan (WSR-88D) Doppler radar station at north tip of Taiwan during part of its lifetime on 6-7 September 2002. The observed rainfall distribution associated with Sinlaku was closely related to the topography in northern Taiwan. Simulation results show that the MM5 initialized diabatically with LAPS has higher skill for precipitation simulation than the non-LAPS cold start experiment, especially for the higher thresholds in the early portion of model integration ( $\geq 10 \mathrm{~mm}$ in 0-6 h). The assimilation of the Wu-Fen-Shan Doppler radar data played a key role in the improvement of precipitation simulation owing to improvement in the presentation of typhoon hydrometeorological features, such as clouds and the outer rainband, in the model initial conditions. The presence of these initial hydrometeor species had a beneficial impact on reduced precipitation spin-up time. The use of Doppler radar data also can enhance the forecast definition of typhoon structure and rainband simulations. However, these radar data only play a minor role on the typhoon track simulation in this case study. Overall, the mesoscale model initialized diabatically with LAPS data assimilation shows improved capability on the typhoon short-range quantitative precipitation forecasts, es-
\end{abstract}

\footnotetext{
${ }^{1}$ Central Weather Bureau, Taipei, Taiwan, ROC

2 NOAA/Forecast Systems Laboratory, Boulder, Colorado, USA

*Corresponding author address: Dr. Guo-Ji Jian, Central Weather Bureau, 64 Kuang Yuan Rd., Taipei, Taiwan, ROC; E-mail: jgj@mfcsv.cwb.gov.tw
} 
pecially when the Doppler radar data is included.

(Key words: Typhoon quantitative precipitation forecasts, LAPS, Diabatic data assimilation, MM5)

\section{INTRODUCTION}

One of the major forecasting technique developments of the Central Weather Bureau (CWB) in Taiwan has been to improve the quantitative precipitation forecasting (QPF) of tropical cyclones. Geographically, Taiwan is one of the regions around the world mostly frequently affected by tropical cyclones. On average, three or four tropical storms (or typhoons) hit Taiwan and one or two of them make landfall annually. Because the enormous damage produced, tropical cyclones are the most serious weather systems in the Taiwan area.

As a tropical cyclone approaches Taiwan, the steep and high altitude topography over the island - Central Mountain Range (Fig. 1, hereinafter, CMR) with highest peak close to $4000 \mathrm{~m}$ -, is a critical factor for the storm's track deflection, local circulation variations, and many extreme rainfall events (Wu and Kuo 1999). For example, both observational (Brand and Blelloch 1974; Wang 1980) and numerical studies (Chang 1982; Bender et al. 1987; Yeh and Elsberry 1993a) showed that the westward moving tropical cyclones tend to experience cyclonic (northward) track deflections, especially for weak or slow moving storms. For circulation, secondary centers can form on the lee side as the vortex approaches (from the east) the central and southern part of the CMR. One of the secondary low centers may develop and replace the original one becoming the main tropical cyclone center (Wang 1980; Yeh and Elsberry 1993b; Lin et al. 1999). As to precipitation, although the rainfall distribution for tropical cyclones affecting Taiwan is often phase-locked with the CMR (Wu and Kuo 1999), the mesoscale precipitation distribution associated with a landfalling typhoon is still a difficult task for numerical weather prediction ( $\mathrm{Wu} 2001$ ). However, the flooding, debris flow, and landslides, caused by heavy rainfall during a typhoon affecting Taiwan, are the primary reasons leading to human fatalities and severe damage. For example, on 31 July and 1 August 1996, Typhoon Herb produced a maximum $24 \mathrm{~h}$ rainfall of $1798 \mathrm{~mm}$ over the CMR (Wu and Kuo 1999). This extreme rainfall caused 51 fatalities and 22 people missing. Damage from Herb was in excess of $\$ 5$ billion (NT). Moreover, in July, August, and September 2001, there were four tropical cyclones - Trami, Toraji, Nari, and Lekima making landfall on Taiwan one after another and resulting in a total of 201 fatalities and 121 missing. Therefore, improving accuracy of tropical cyclone precipitation forecasts is very important scientific and forecasting endeavor in Taiwan.

To improve precipitation forecasts, the high-resolution mesoscale model holds some promise. Furthermore, computers have grown greatly in capability recently. Microphysical schemes, those were once only used in research before the 1990's, are being adopted by operational numerical weather prediction models. This will improve the explicit forecasts of clouds and precipitation. However, an accurate quantitative precipitation forecast remains one of the most difficult tasks in meteorology (Businger et al. 1990). During the past decades, there was more improvement in numerical forecasts of the mass and wind field than precipitation fore- 
casts (Olson et al. 1995). One reason is attributable to the complicated and ill-understood precipitation physics. Another important reason is that most model initialization routines provide adiabatic initial conditions, leading to the infamous spin-up problem (Heckley 1985; Donner 1988). The associated lack of condensation and latent heat release during the early part of model integration, restricts the short-range $(0-12 \mathrm{~h})$ forecasting accuracy of mesoscale models.

To address the spin-up problem in limited-area models, data assimilation that includes the diabatic heating effect is commonly used (e.g., Molinari 1982; Davidson and Puri 1992; Chang and Holt 1994). A more advanced and systematic approach is LAPS (Local Analysis and Prediction System; McGinley et al. 1991; Albers et al. 1996). The Forecast Systems Laboratory (FSL) of the National Oceanic and Atmospheric Administration (NOAA) has developed data assimilation system that ingests radar, satellite, profiler, aircraft reports, and conventional data. A unique aspect of LAPS is production of a three dimensional cloud field including vapor, water, ice, mixing ratios and vertical motion estimates (Albers et al. 1996). The resulting fields are used to initialize a range of mesoscale models (e.g., MM5 (Shaw et al. 2001), RAMS (Snook et al. 1996), WRF) with all microphysical species, which are in mass and momentum balance in model initial conditions (Schultz and Albers 2001; McGinley and Smart 2001). Using LAPS, the FSL began initializing real-time forecast system by Pennsylvania State University and the National Center for Atmospheric Research (PSU-NCAR) Fifth-Generation Mesoscale Model (MM5) since the fall of 2000. Based on experimental runs for the Colorado forecasting domain, the preliminary quantitative evaluation of prediction showed improved skill in forecasting clouds and precipitation in the early part (0-6 h) of the forecasts (Shaw et al. 2001). Due to its unique diabatic initialization technique, it has been dubbed the "hot start" MM5 forecast. This will hereinafter referred to as LAPS/MM5.

Abundant data at the CWB provides an opportunity for data assimilation and short-range quantitative forecasts. Through a collaborative project with NOAA/FSL, the CWB has run LAPS analysis since 1999. Hourly analyses of the atmospheric state variables, clouds, precipitation, and surface variables are produced daily using radar, satellite, soundings, aircraft observations, and surface mesoscale network observational data. Furthermore, to improve the QPF of tropical cyclones and the heavy rainfall events during the warm season in the Taiwan area, development and application of the LAPS/MM5 operational system are part of ongoing efforts at the CWB.

The primary purpose of this paper is to test the effects of LAPS diabatic initialization on the simulated precipitation associated with Typhoon Sinlaku (2002) over the complex topography in Taiwan area since there is evidence for sensitivity of typhoon prediction to data assimilation and diabatic initialization (Shi et al. 1996; Karyampudi et al. 1998). Typhoon Sinlaku was selected because Doppler radar is one of the most important data sources for an accurate analysis of typhoons and Sinlaku was located close to the Wu-Fen-Shan (WSR-88D) Doppler radar station during part of its lifetime on 6-7 September 2002. Therefore, there were radar radial velocities and reflectivity data to enhance the LAPS diabatic initialization. In this study, we will address specific questions, such as 1) whether LAPS diabatic initialization will provide a superior simulated precipitation to the non-LAPS cold start (no hydrometeors in initial fields), and 2) whether the Wu-Fen-Shan Doppler radar data play a key role on the 
simulated precipitation associated with Sinlaku over Taiwan. In the following section, the LAPS analysis and data are presented. Section 3 provides the mesoscale model and experimental design. Section 4 presents the general comparisons of Typhoon Sinlaku between the simulations and observations. In section 5, simulated precipitation is verified against observational data from 391 rain gauges in Taiwan (see Fig. 1 for locations). The discussions and conclusions are provided in the final section.

\section{DATA AND LAPS ANALYSIS}

LAPS was developed in the early 1990's and has undergone continuous improvements at FSL. It was designed to combine all available meteorological data sources into a single, coher-

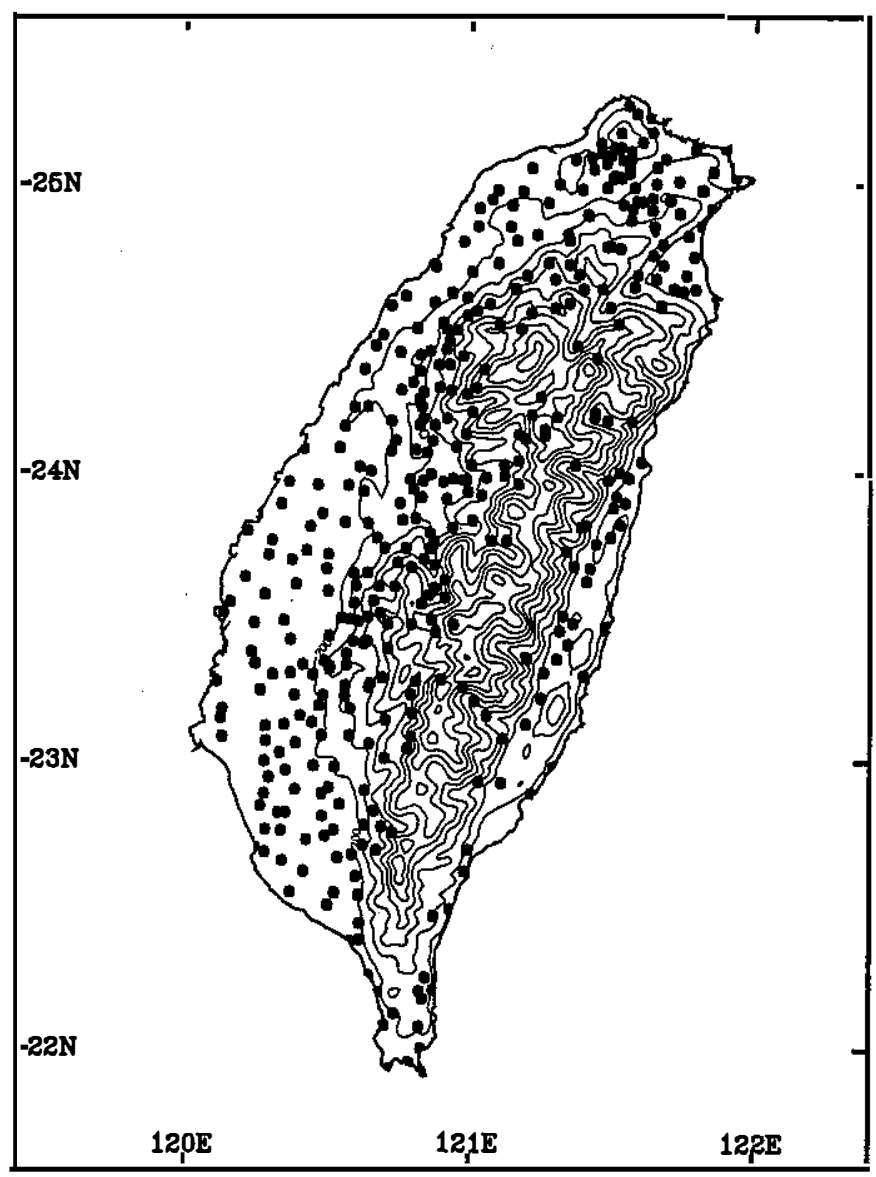

Fig. 1. Terrain map of Taiwan. Contours are drawn from $200 \mathrm{~m}$ height with an interval of $300 \mathrm{~m}$. The filled circles indicate the locations of the 391 rain gauge stations. 
ent three-dimensional depiction of the atmosphere. Within the CWB, LAPS is run routinely on a domain covering approximately 1.75 million square kilometers (Fig. 2a) using a 153 by 141 horizontal grid with a $9 \mathrm{~km}$ grid spacing. This domain contains 21 pressure levels with a 50 $\mathrm{hPa}$ vertical spacing ranging from $1100 \mathrm{hPa}$ through $100 \mathrm{hPa}$. Over this domain, the atmospheric state variables, clouds, precipitation, and surface variables (which can be used as a nowcasting tool) are produced hourly.

\subsection{Background Setup and Observational Data}

Like most analysis systems, LAPS relies on another limited-area or global model grids data for a first guess. Typically the limited-area model from the CWB (with a $15 \mathrm{~km}$ horizontal grid spacing) is used for Taiwan domain. As to the initialization methods for the CWB limitedarea model, the optimum interpolation objective analysis is applied to include the sounding data, surface observational data, pilot balloon wind and aircraft meteorological reports into the CWB global model data (with a $1^{\circ}$ horizontal resolution) for generating the initial conditions of the CWB limited-area model. However, most of the first guess information for LAPS is provided with relatively coarse resolution. Typically the structure of tropical cyclones contained in the first guess is relatively broad and weak, and unless there is abundant data over the sea to support analysis of the typhoon structure. The initial analysis from LAPS will also be too weak. Therefore, LAPS has an optional function to insert a vortex, that is closer to the observed one, into the first guess field before processing atmospheric analysis. In this procedure, a bogussing scheme similar to the NCAR-AFWA (Air Force Weather Agency) procedure (Davis and Low-Nam 2001) is applied. For this typhoon case study, the maximum tangential wind speed, the radius of maximun wind (RMW) and the exponential parameter, which specifies the horizontal wind profile outside the RMW of the Rankine vortex are $45 \mathrm{~m} \mathrm{~s}^{-1}, 90 \mathrm{~km}$, and 0.8 , respectively.

After setting up the first guess fields, LAPS ingests the available observational data. Within the CWB, the data collected routinely include the following (see Fig. 2 for locations) :

- Surface observations (include synoptic stations, ships, and buoys) and hourly meteorological aviation routine weather report (hereinafter, METAR) data.

- Wu-Fen-Shan (WSR-88D) Doppler radar volumn scans at 6 minute intervals were ingested in this study (Chi-Ku, Ken-Ting, and Hua-Lian Doppler radar data were also available since October 2002).

- Geostationary Meteorological Satellite (GMS-5) infrared $11 \mu \mathrm{m}$ and visible data.

- Rawinsonde sounding data.

- Automated and voice reports from aircraft at random times.

As another option, when configured to initialize a mesoscale model (e.g., MM5), LAPS can use that model's result as background field. Consequently, a full data assimilation cycle can be established.

\subsection{Wind Analysis}

The analysis procedure for winds uses all the data sources in a two-pass objective analysis 


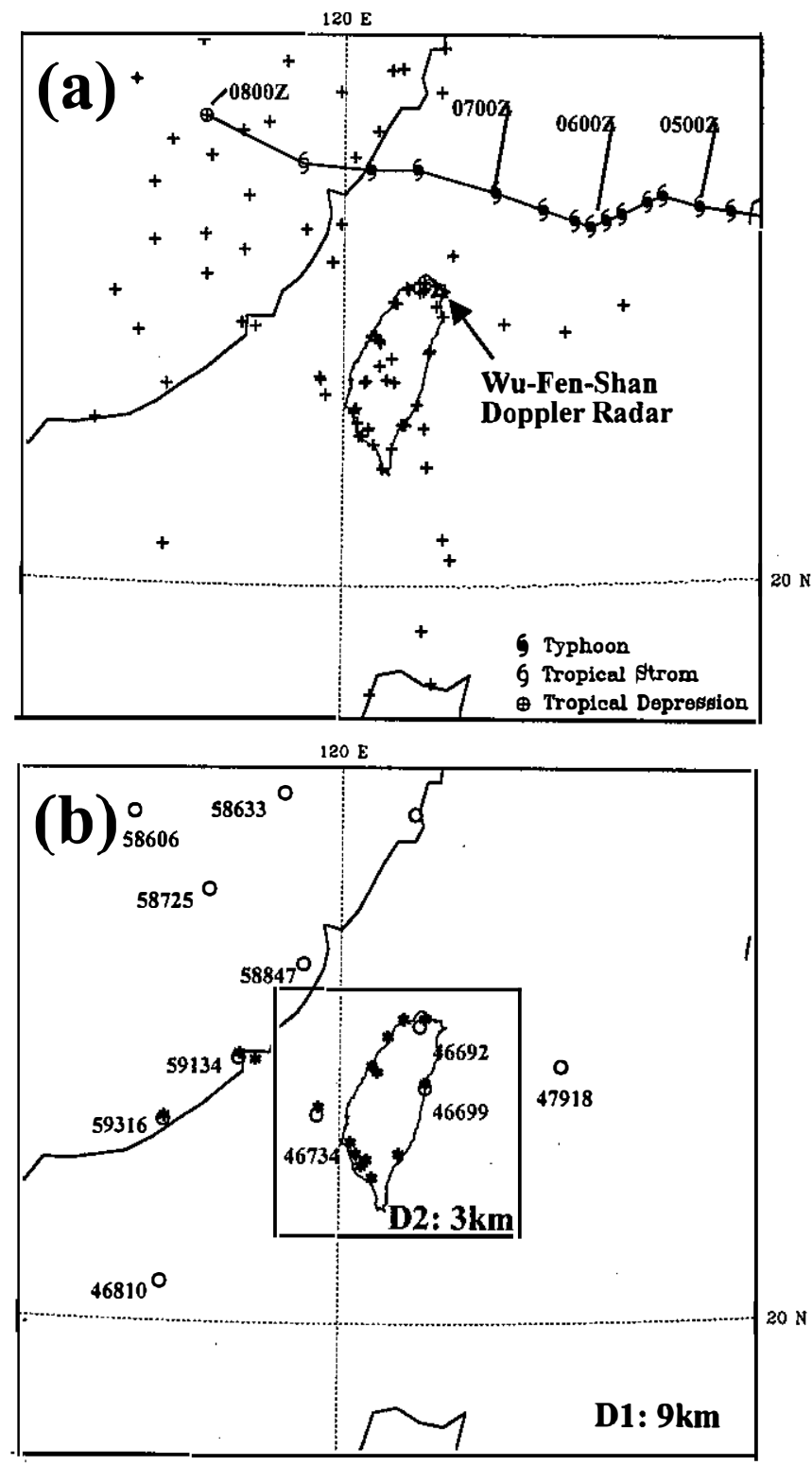

Fig. 2. (a) Domain configuration of LAPS analysis. The plus signs indicate the surface observation stations. The triangle sign shows the location of the Wu-Fen-Shan Doppler radar station. Also shown on the map in the best track of Typhoon Sinlaku from CWB (6 h interval). (b) Domain configuration for MM5 simulation. A stationary $3 \mathrm{~km}$ domain (D2) is nested within a $9 \mathrm{~km}$ domain (D1) using two-way nesting interfaces. The stars and circles signs indicate the meteorological aviation routine weather report (METAR) and the sounding stations, respectively. 
(Albers 1995). A preliminary analysis is a smooth blending with the model background using surface observational data, sounding, and aircraft reports. The $u$ and $v$ wind components are analyzed independently utilizing multiple-pass Bames (1964) scheme with a successive correction method to distribute these observations onto the LAPS grid. With each analysis pass, the radius of influence is decreased to get finer scale structure and match the observations more closely.

The next step is similar to the above except that Doppler radial velocities are added. To generate wind vectors using these radar observations, Doppler radial velocities are first mapped onto the LAPS grid. A noise-filtering algorithm is used to control the quality of the mapped velocities. Next, for each grid point containing a radial velocity measurement, the tangential wind component is estimated from the analysis in the preliminary step. The radial and tangential components are then combined to produce a wind vector. This wind vector is then assumed to be a wind data source no different from the in situ wind observations. These are decomposed into $u$ and $v$ wind components, and the successive corrections analysis is run again to generate the three-dimensional wind field.

\subsection{Surface and Temperature Analysis}

The current version of LAPS produces a complete set of 21 surface products hourly, including all the standard meteorological variables and other useful fields, such as terraininduced verical motion and surface-based lifted index. The LAPS surface analysis procedure also uses successive correction iteration matching the observations. After that, a variational method developed by Lewis (1971) is used to constrain the pressure and wind fields to satisfy the full equations of motion. Vector wind changes from an earlier analysis, usually the previous hour, are used to provide an estimate of the time tendency terms. A more detailed of LAPS surface analysis is available in McGinley et al. (1991).

The three-dimensional temperature analysis (Albers et al. 1996) is produced using a smooth blending of sounding temperatures at upper levels, the LAPS surface temperature analysis at lower levels, and the CWB limited-area model data. The algorithm also involves a multiplepass Barnes (1964) scheme with successive correction and a decreasing radius of influence with each analysis pass.

\subsection{Cloud Analysis}

One of the unique components of LAPS is the cloud analysis (Albers et al. 1996), designed to provide the user with a complete description of the cloud field. On the Taiwan analysis domain, vertical cloud information from METAR data (see Fig. $2 b$ for locations) and the humidity field of the CWB limited-area model were analyzed horizontally to generate a preliminary cloud analysis. This procedure provides information on the vertical location and approximate horizontal distribution of cloud layers. The satellite cloud-top temperature field, which is derived from GMS-5 IR $11 \mu \mathrm{m}$ channel, is converted to a cloud-top height field with the assistance of the LAPS three-dimensional temperature field. The next step is inserting the cloud-top height field into the preliminary cloud analysis for twofold effects. One is to get 
better cloud-top heights and the other is to increase the horizontal spatial information content of the cloud analysis. In this step, there is a set of rules to resolve the conflicts between METARs and satellite data. Generally speaking, the METAR data dominated the analysis of low or warm clouds and the coverage of the cloud layers was controlled by the satellite data. The $\mathrm{Wu}$ Fen-Shan Doppler radar reflectivity field is next inserted and treated as a region of cloud. Finally, the GMS-5 visible satellite data is inserted to further define the cloud cover analysis.

An additional step is the retrieval of cloud microphysical data using a streamlined version of the Smith-Feddes model (Haines et al. 1989). Moreover, the analyzed clouds are typed utilizing a table based on stability and temperature. From the type and depth of each cloud layer, an appropriate vertical motion profile is determined for each vertical column containing clouds (Schultz and Albers 2001).

\subsection{Moisture Analysis}

The LAPS water vapor analysis run routinely at FSL utilizes GOES-derived layer precipitable water data (GVAP), Global Positioning System (GPS) vapor delay data, LAPS clouds, LAPS surface moisture, and background model moisture to generate the three-dimensional moisture field consistent with these moisture integrations sensors. The variational framework (Birkenheuer 2001) strategy allows different data sources to be represented by different terms in the minimized functional. This module designed to reconcile the cloud and vapor analysis, is the last process run prior to the dynamic balance scheme. Currently the CWB moisture analysis, has no data similar to the GVAP and GPS data so this procedure only includes LAPS clouds, LAPS surface moisture, sounding data and background model moisture.

\subsection{Balance Scheme}

The purpose of the dynamic balance package (McGinley and Smart 2001) is to ensure that the momentum and mass fields are consistent with the cloud-derived vertical motions. Using input fields of state variables previously derived as "observations" (each field comes with estimates of analysis error at each grid point), this adjustment step is designed to develop interconsistency among mass, winds, input vertical motions and clouds. This scheme employs several dynamical consuraints within a three-dimensional, variational formulation to adjust the wind, temperature, and height fields based on the background model vertical velocity field and the diagnosed cloud vertical motions from the cloud analysis. During the minimization of the variational cost function in this step, the Eularian time tendencies of $u$ and $v$ wind components are also minimized, which couples mass to momentum fields. Furthermore, the divergent wind components vary so that $u$ and $v$ wind components balance with vertical velocities to reduce model shock in the first few time steps. The result is an initial field consistent with background and analysis error variance, and a three-dimensional wind field consistent with the input cloud vertical motion. The net effect is instant spin up of precipitation. This diabatic initialization package is the crucial element seeking to improve precipitation forecasts during the first few hours of the numerical weather prediction run. 


\section{MODEL CONFIGURATION AND EXPERIMENT DESIGN}

\subsection{The Mesoscale Model}

The PSU-NCAR MM5 (version 3.5) is configured in nonhydrostatic mode for short-range forecasting at the CWB. The domains, shown in Fig. 2b, are a stationary $3 \mathrm{~km}$ domain of 151 by 151 grid points nested within a $9 \mathrm{~km}$ domain using two-way interfaces. The horizontal size and geographic location of the outer domain are the same as the LAPS analysis domain. Both MM5 domains extend in the vertical to $100 \mathrm{hPa}$ and are resolved by 30 unevenly spaced sigma levels, with the finest resolution near the boundary layer. Two-minute-averaged terrain data are analyzed to model grids using a Cressman (1959) analysis scheme and filtered by a twopass smoother/desmoother. For initializing the various surface categories and coastline, a twominute-averaged vegetation/land-use and land-water mask dataset from U.S. Geological Survey are used. Initial atmospheric conditions are provided by LAPS, sea surface temperature from the National Centers for Environmental Prediction (NCEP), and lateral boundary conditions of outer domain from the CWB limited-area model. For the nested domain, the initial conditions are generated from its parent mesh.

For the physics options, the explicit moisture scheme of Schultz (1995) is used, which includes prognostic equations for cloud ice and water, snow, rain, and graupel. The surface and PBL are parameterized using the five-layer soil model and medium-range forecasting (MRF) PBL scheme (Hong and Pan 1996). The Rapid Radiative Transfer Model (RRTM) of Mlawer et al. (1997) is applied and no cumulus parameterization is used. In addition, Klemp and Durran's (1983) upper radiative boundary condition is applied to allow wave energy to pass through the model top.

\subsection{Experiment Design}

Simulations were conducted with the LAPS/MM5 system to test its effectiveness forecasting the precipitation associated with Typhoon Sinlaku in the Taiwan area. Three simulations (see Table 1) are initialized at 0000 UTC 6 September 2002 and integrated for $24 \mathrm{~h}$. The first experiment used both the operational model physics and the LAPS diabatic initialization for initial conditions. This is the control run (referred to as CTRL) for the homogeneous comparison with other experiments. The second one (referred to as CLDS), with the same model configuration as CTRL, but utilized only the CWB limited-area model data as a non-LAPS cold start initialization. The third experiment (referred to as NRAD) excluded the Wu-FenShan Doppler radar data from CTRL to study the impact of Doppler radar data on the precipitation simulation.

\section{GENERAL COMPARISON OF TYPHOON SINLAKU}

A reasonable track and intensity prediction are the prerequisite for a good precipitation forecasts for a typhoon affecting Taiwan (Shieh et al. 1997). Therefore, before verifying the model precipitation, the simulated track, intensity, and horizontal wind field are compared 
Table 1. Summary of the simulation experiments

\begin{tabular}{ccc}
\hline Experiment & $\begin{array}{c}\text { Using Wu-Fen-Shan } \\
\text { Doppler radar data }\end{array}$ & $\begin{array}{c}\text { LAPS analysis and } \\
\text { diabatic initialization }\end{array}$ \\
\hline CTRL & Yes & Yes \\
CLDS & No & No \\
NRAD & No & Yes \\
\hline
\end{tabular}

with the analyses from CWB in this section. Furthermore, to examine how well the LAPS cloud field fits to the observations, the cloud-top temperature and radar reflectivity during the early portion of the integration are also compared to show the performance of LAPS/MM5 simulation.

\subsection{Life History of Sinlaku and Rainfall Distribution in Taiwan}

Typhoon Sinlaku originated from a disturbance that formed over western North Pacific in late August 2002. It intensified and moved northwestward located approximately $1200 \mathrm{~km}$ east-northeast of the Guam Islands on 29 August. The track and intensity of Sinlaku are shown in Fig. 3. According to the official report of the CWB, Sinlaku was designated a ropical storm at 0600 UTC 29 August and a typhoon at 1200 UTC 30 August. Around 0000 UTC 31 August, Sinlaku turned westward along the southern edge of a subropical ridge and reached its maximum intensity at 0600 UTC 2 September with an estimated maximum sustained wind of $43 \mathrm{~m}$ $\mathrm{s}^{-1}$ near its center and a minimum sea-level pressure of $950 \mathrm{hPa}$. On 5 September, it gradually decelerated and turned southwestwards while centered just northeast of Taiwan. At around 1200 UTC 6 September, Sinlaku veered to a westward rack and began to accelerate and passed through the sea north of Taiwan. It made landf all over the Zhejiang province of China at around 1200 UTC 7 September (see Fig. 2a and Fig. 3). Due to the presence of strong surface friction and smaller surface heat fluxes over land, Sinlaku weakened to a tropical storm at 1800 UTC 7 September and then to a tropical depression at 0000 UTC 8 September.

For the rainfall distribution in the Taiwan area, rain gauge data for a network of stations in Taiwan were obtained from the CWB. The precipitation associated with Sinlaku over the island mostly occurred on 6 September and were analyzed every $6 \mathrm{~h}$ (Fig. 4). During the first $6 \mathrm{~h}$ interval (0600-0606, Fig. 4a), four major precipitation centers were identified: Three on the steep windward slopes of the northern portion of the CMR and the other at Yang-Ming Mountain located at the north tip of Taiwan. During the next two $6 \mathrm{~h}$ intervals (0606-0612, Fig. 4b; 0612-0618, Fig. 4c), the rainfall amounts were less than the first $6 \mathrm{~h}$. However, the locations of major precipitation area were very similar. During the last $6 \mathrm{~h}$ (0618-0700, Fig. 4d), the peak accumulations were around $82 \mathrm{~mm}$ and located at Yang-Ming Mountain. The other moderate accumulations were still at the northern CMR. Generally speaking, the rainfall distribution was phase-locked with the complex topography over northern Taiwan during Sinlaku passing through the sea north of Taiwan. 


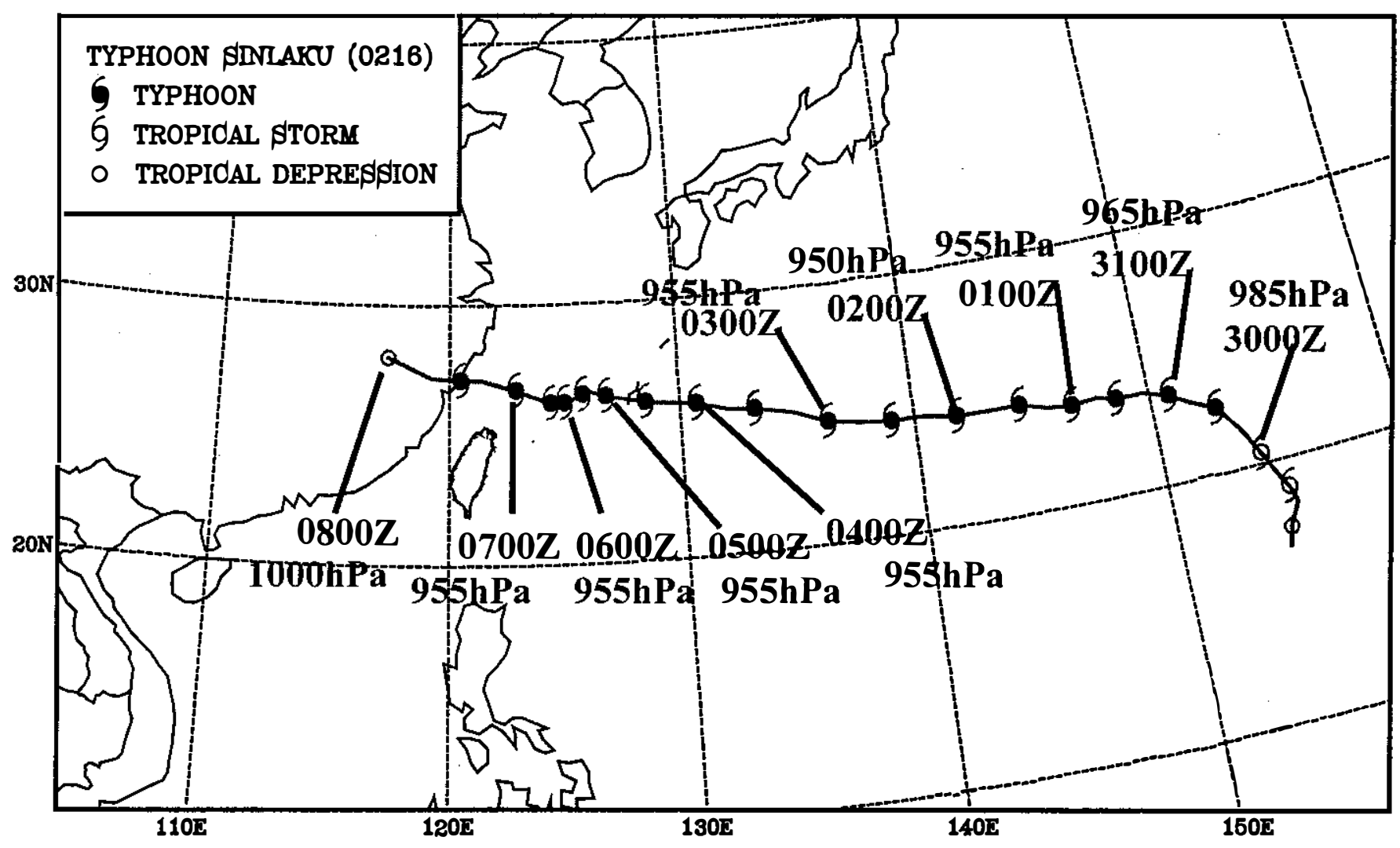

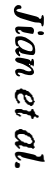

Fig. 3. Track and intensity (tropical cyclone stage and minimum sea-level pressure in $\mathrm{hPa}$ ) of Typhoon Sinlaku in $12 \mathrm{~h}$ intervals between 30 August and 8 September 2002. 

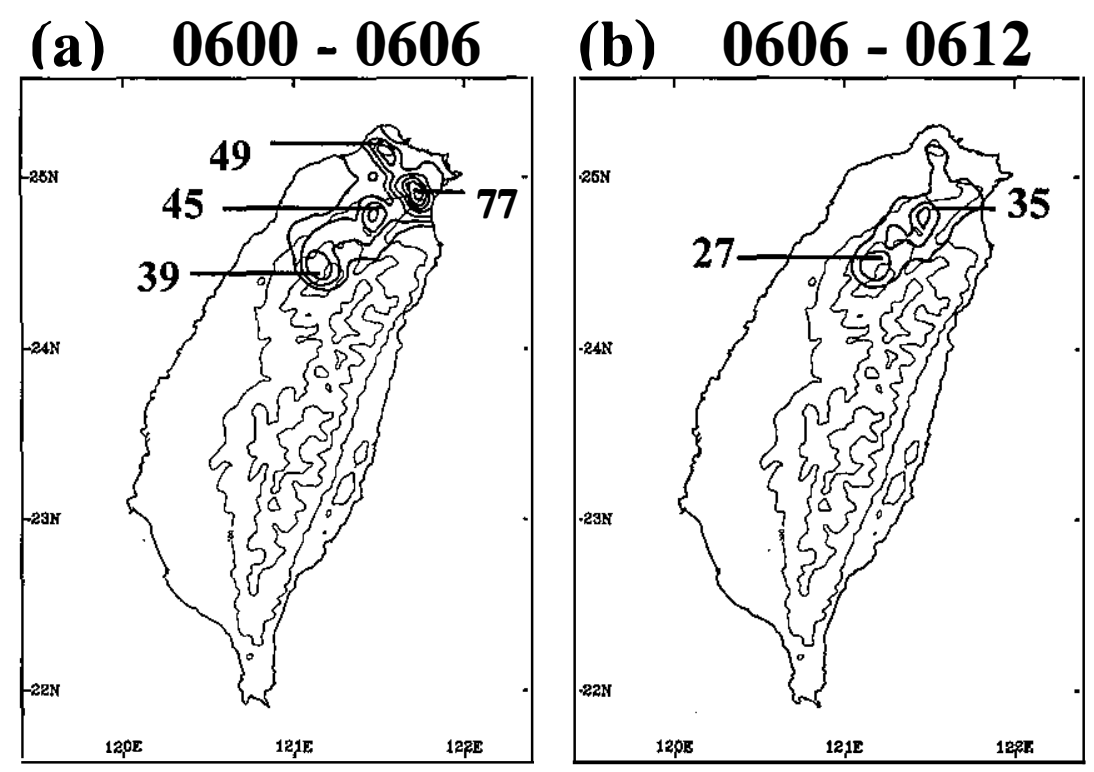

(c) $0612-0618$
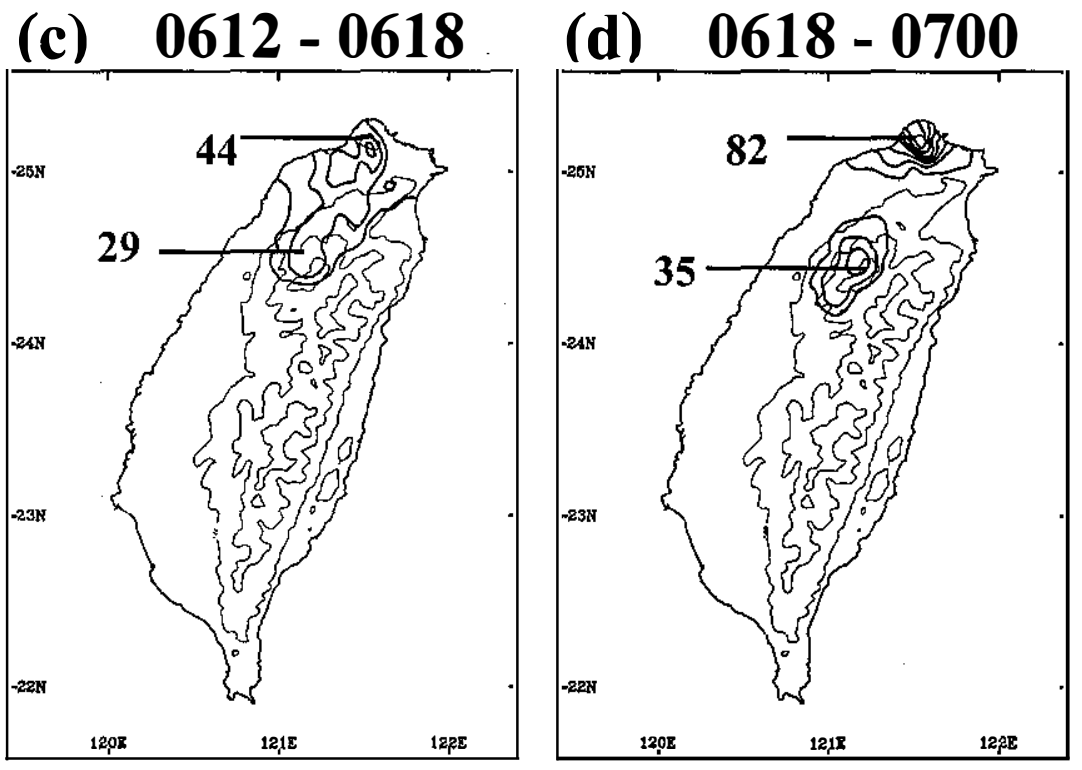

Fig. 4. Observed accumulated precipitation (with a contour interval of $10 \mathrm{~mm}$ ) associated with Typhoon Sinlaku for the (a) $6 \mathrm{~h}$ period ending 0600 UTC 6 September 2002, (b) $6 \mathrm{~h}$ period ending 1200 UTC 6 September 2002, (c) $6 \mathrm{~h}$ period ending 1800 UTC 6 September 2002, and (d) $6 \mathrm{~h}$ period ending 0000 UTC 7 September 2002. Taiwan terrain height (thin lines) is also shown with a contour interval of $1000 \mathrm{~m}$. 


\subsection{Track and Intensity}

The comparison of the tracks from CTRL, CLDS, NRAD, and the $6 \mathrm{~h}$ analysis from the CWB are shown in Fig. 5. The analyzed storm moved southwestward slowly in the first $6 \mathrm{~h}$ and then straight northwestward, whereas the storm propagated northwestward directly in CTRL (Fig. 5a); and north-northwestward, turning northwestward in CLDS (Fig. 5b). Furthermore, the simulated typhoon in CLDS translated slower than the analyzed in the first $6 \mathrm{~h}$ and faster during 6-18 h. In CTRL, even though moved a little faster than the analyzed in the first $6 \mathrm{~h}$, the predicted track was better than in CLDS. These differences were likely caused by the different model initial conditions in the simulations. As to NRAD (Fig. 5c), the storm moving behavior was similar to in CTRL. This suggests that the Wu-Fen-Shan Doppler radar data contributed the minor effect to the motion of Typhoon Sinlaku on 6 September.

Along with the horizontal wind fields, the winds at the lowest model level $(\sigma=0.99)$ reveal that the $12 \mathrm{~h}$ simulation of CTRL case (Fig. 5a) yielded a localized area of winds greater than $39 \mathrm{~m} \mathrm{~s}^{-1}$ in the west quadrant of the storm and winds greater than $30 \mathrm{~m} \mathrm{~s}^{-1}$ extending outward about $160 \mathrm{~km}$ from the center. The CLDS case (Fig. $5 \mathrm{~b}$ ) produced an asymmetric pattern with maximum wind values on the northeast side of the storm and the area of winds greater than $30 \mathrm{~m} \mathrm{~s}^{-1}$ was smaller than in CTRL. Furthermore, there were also significant differences in the winds between CTRL and NRAD (Fig. 5c). The areal coverage of strong winds was more extensive if the Doppler radar data was included. These results imply that the wind structure of the typhoon is very sensitive to the model initial conditions.

For typhoon intensity, the time series of the simulated and subjective analyzed minimum sea-level pressure from the CWB for the $24 \mathrm{~h}$ period are shown in Fig. 6. Although the initial storm intensity in all three simulations somewhat weaker than the analyzed intensity from the CWB, the maintenance of storm strength was favorable in those simulations.

\subsection{Clouds and Radar Reflectivity during the Early Portion of Simulations}

The most important differences in the initial conditions between CTRL and CLDS are in the specification of microphysical species. For a typhoon simulation, the routine rawinsonde and ship data are usually too sparse to capture the mesoscale features in the initial typhoon structure. Therefore, the CTRL processed the LAPS cloud analysis (see section 2.4) to introduce estimates of microphysical species in the initial conditions and obtain a dynamic balance with the mass and momentum fields. To see how well the cloud analysis compares to the GMS-5 brightness temperature, the cloud-top temperature fields of CTRL, CLDS, and the infrared satellite image are compared in Fig. 7. The initial cloud-top temperature distribution of CTRL (Fig. 7b) compares well to the satellite observation (Fig. 7a). This shows the advantage of using LAPS cloud analysis to input cloud information into the model. After a $3 \mathrm{~h}$ simulation, the cloud pattern of CTRL (Fig. 7c) is similar to the satellite cloud observation (not shown) in the outer regions, but there is less correspondence in the inner core regions of typhoon. This error was caused by at least three factors. First, the eyewall regions of Sinlaku were located in the outer MM5 gridded domain (see Fig. 2b) during the simulation and the grid spacing of $9 \mathrm{~km}$ was not able to resolve the inner core dynamics of the typhoon. Second, the 
(a) CTRL 1200 UTC 6 Sept.

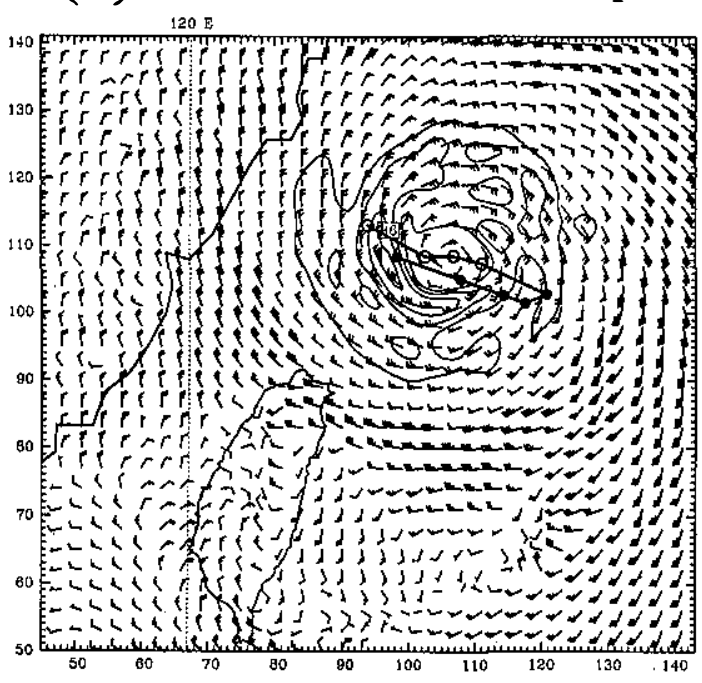

\section{(c) NRAD 1200 UTC 6 Sept.}

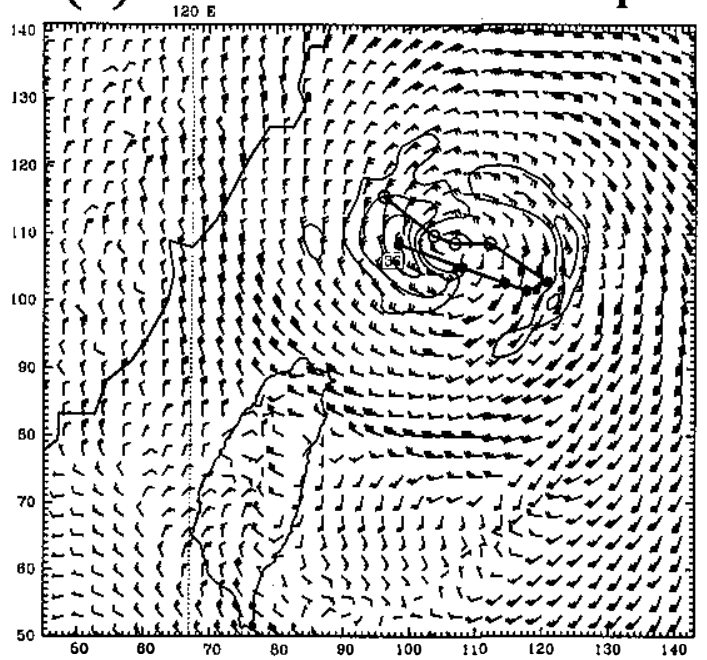

(b) CLDS 1200 UTC 6 Sept.



Fig. 5. Wind and isotach (starts at $30 \mathrm{~m} \mathrm{~s}^{-1}$, with a contour interval of $3 \mathrm{~m} \mathrm{~s}^{-1}$ ) at $\sigma=0.99$ from (a) CTRL, (b) CLDS, and (c) NRAD at 1200 UTC 6 September 2002. The analysis from the CWB (filled circles) and simulated (open circles) tracks of Typhoon Sinlaku are also shown in $6 \mathrm{~h}$ interval.

limitations of satellite and radar coverage to specify the initial conditions still introduced errors in defining the eyewall structure of the initial vortex. The third possible factor was from the model physics (e.g., cloud microphysics, boundary layer processes). However, comparing CTRL (Fig. 7c) and CLDS (Fig. 7d), the CTRL yielded much better results than the CLDS (still in spin-up period). This shows that the LAPS/MM5 system may help to reduce the model spin-up time.

Doppler radar data is another important data source of the LAPS cloud analysis. For the typhoon rainbands, we compared the simulations of CTRL, CLDS, and NRAD at $1 \mathrm{~km}$ mean 


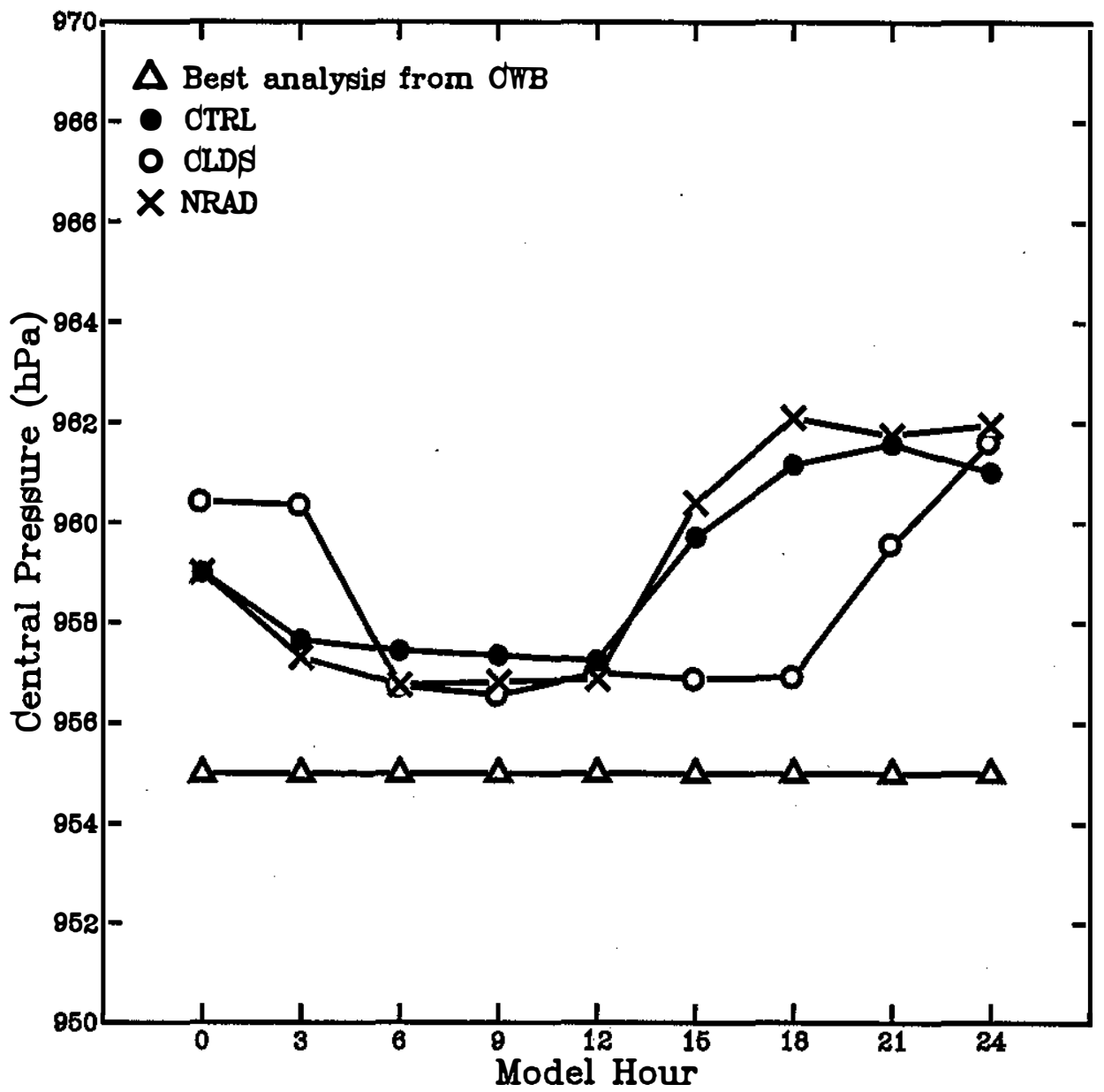

Fig. 6. Time series of the minimum sea-level pressure (hPa) from the CWB analysis and simulations from 0000 UTC 6 to 0000 UTC 7 September 2002.

sea-level (MSL) in Fig. 8. Moreover, the observations space (CV map) from Wu-Fen-Shan radar station are shown (Fig. 8a) only for pattern comparison because the observed reflectivity was not exactly at $1 \mathrm{~km}$. Besides, the coverage of the Wu-Fen-Shan Doppler radar was only a half and localized in the southwest side of the typhoon. The related visible satellite image is also shown (Fig. 8b) for rainbands comparison. The observed radar data (Fig. 8a) indicated a wide outer rainband on the southwest side of the storm, which spread over the sea north of Taiwan and the partially inland area of the northern Taiwan. Furthermore, the visible satellite image (Fig. 8b) showed another two typhoon rainbands on the north and the southeast side of the storm. In CTRL (Fig. 8c), the simulated radar reflectivity field shows the reasonable results in areal coverage and locations of the rainbands. However, in NRAD the simulated rainband near Taiwan was narrower than the observations (Fig. 8e) and was completely absent in CLDS 
(a) GMS-5 IR 0000 UTC 6 Sept.


(c) CTRL ${ }_{100}^{0300}$ UTC 6 Sept.

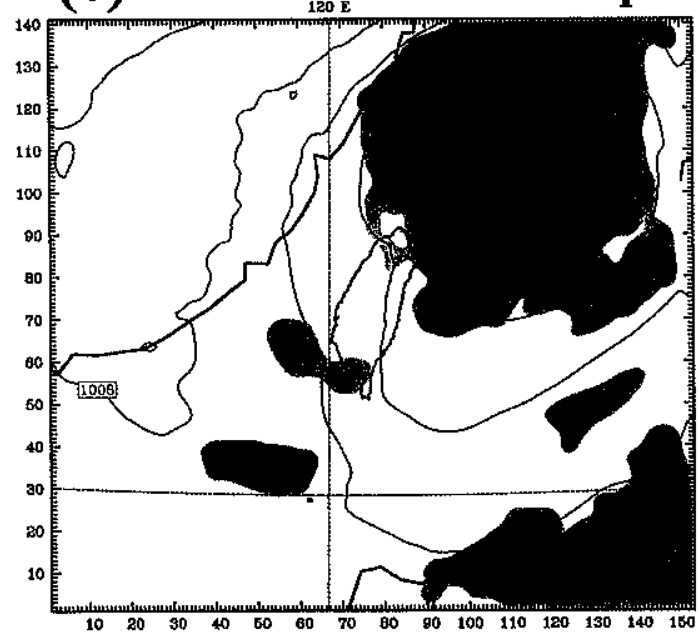

(d) CLDS ${ }_{\text {tro }}^{0300}$ UTC 6 Sept.
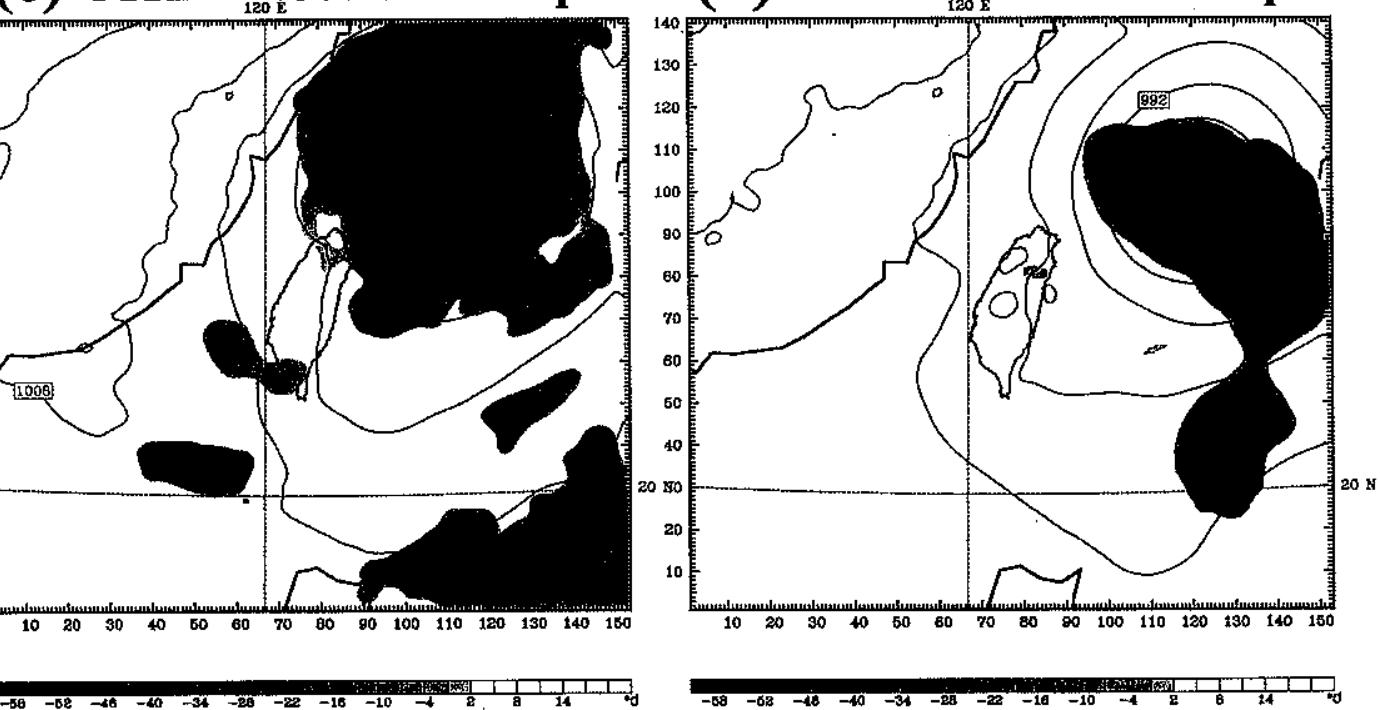

Fig. 7. GMS-5 IR satellite photograph and simulated cloud-top temperature deduced from MM5 cloud ice, water, and hydrometeor: (a) GMS-5 IR at 0000 UTC 6 September 2002, (b) initial fields from CTRL at 0000 UTC 6 September 2002, (c) simulation from CTRL at 0300 UTC 6 September 2002, and (d) simulation from CLDS at 0300 UTC 6 September 2002. Distributions of simulated sea-level pressure are also shown with a contour interval of $4 \mathrm{hPa}$. 
(a) RCWF 0300 UTC 6 Sept.

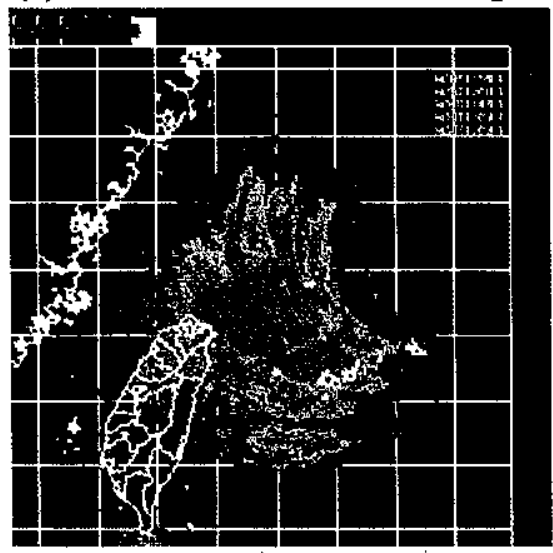

(c) CTRL 0300 UTC 6 Sept.

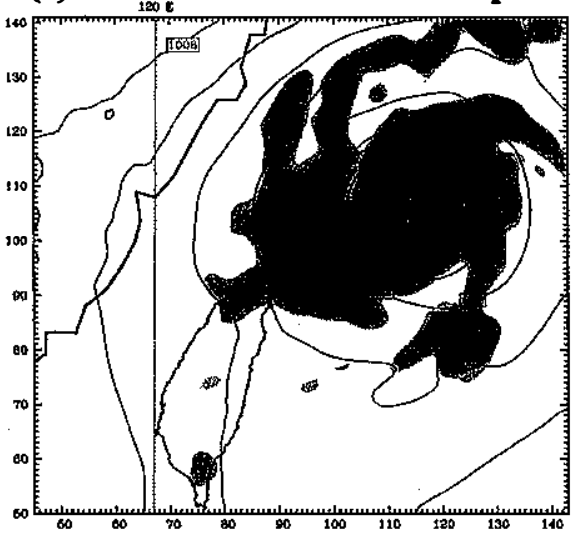

(e) NRAD 0300 UTC 6 Sept.

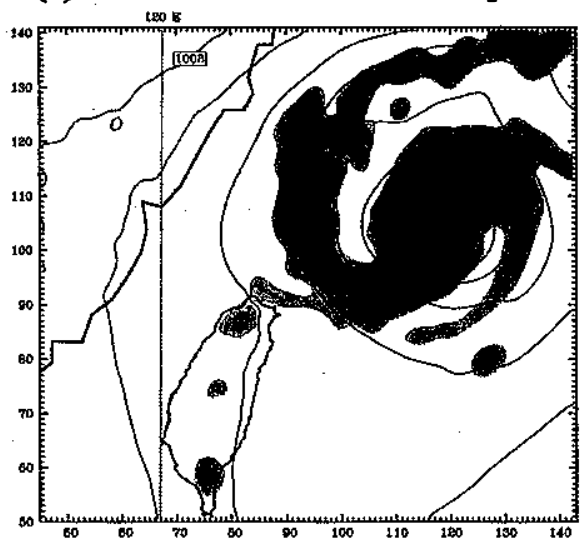

(b)GMS-5 VIS 0300 UTC 6 Sept.



(d) CLDS 0300 UTC 6 Sept.

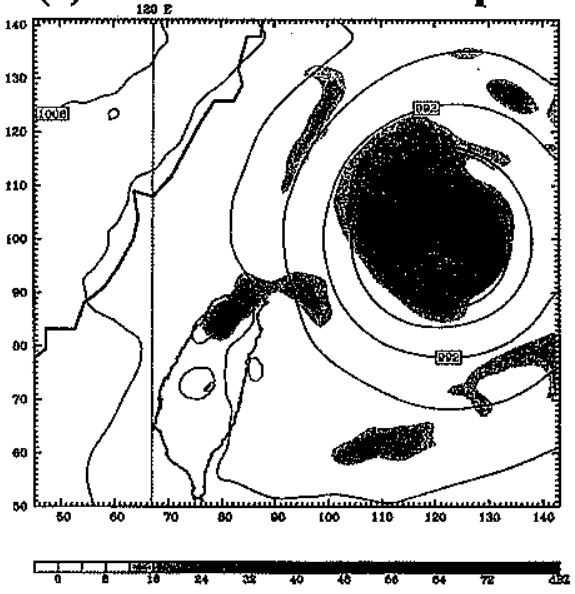

Fig. 8. (a) Radar reflectivity from the WuFen-Shan (RCWF) NEXRAD radar at 0300 UTC 6 September 2002. (b) GMS-5 visible satellite photograph at 0300 UTC 6 September 2002. The simulated radar reflectivity patterns at $1 \mathrm{~km}$ above mean sea level from (c) CTRL, (d) CLDS, and (e) NRAD at 0300 UTC 6 September 2002. Distributions of simulated sea level pressure are also shown with a contour interval of $4 \mathrm{hPa}$. 
(Fig. 8d). These results reveal that the CTRL was superior to CLDS again and the importance of Doppler radar data in creating the initial conditions in the typhoon rainbands simulation.

\section{PRECIPITATION VERIFICATION}

\subsection{The Verification Method}

In this study, the precipitation from the nested model domain $(3 \mathrm{~km})$ will be verified against observational data from 391 rain gauge stations in Taiwan using the method as in Colle et al. (1999). While rain gauge data are not perfect for model evaluation, the extensive network over Taiwan seems a sufficient way to get observed precipitation coverage. Due to the irregularly distributed rain gauge stations over the island, the precipitation from the model grid was interpolated to each rain gauge site using an inverse distance Cressman (1959) method:

$$
P=\frac{\sum_{n=1,4} W_{n} P_{n}}{\sum_{n=1,4} W_{n}},
$$

where $P_{n}$ is the forecast precipitation at the four model grid points surrounding the rain gauge site. The weighting function $W_{n}$ is given by

$$
W_{n}=\frac{R^{2}-D_{n}^{2}}{R^{2}+D_{n}^{2}}
$$

where $R$ is the model horizontal grid spacing ( $3 \mathrm{~km}$ in this study) and $D$ is the horizontal distance from the model grid point to the rain gauge site.

To evaluate the performance of the model precipitation objectively, the equitable threat score (ETS; Schaefer 1990) and bias score were calculated for given precipitation thresholds exceeding $0.5,1,2.5,5,10,15,20$, and $25 \mathrm{~mm}$. The ETS and bias score are defined as

$$
\begin{aligned}
& E T S=\frac{H-E}{F+O-H-E}, \\
& \text { Bias }=\frac{F}{O},
\end{aligned}
$$

where $H$ is the number of points where rainfall was correctly forecasted to exceed the specified threshold, $F$ is the total number of points where rainfall was forecasted to exceed the 
threshold, $O$ is the number of occurrences where the observations exceeded the threshold, and $E$ is the number correct forecast occuring by chance:

$$
E=\frac{F O}{N},
$$

where $N$ is the total number of points being verified.

The bias score reveals overforecasting (bias $>1$ ) and underforecasting (bias $<1$ ) by the model. ETS measures the agreement between a forecast and an observed rainfall pattern, with ETS $=1$ for a perfect forecast and ETS $=0$ for a random forecast. To examine further the precipitation results during the early portion $(0-6 \mathrm{~h})$ of the simulations, the root-mean-square error (RMSE) and correlation coefficient (Corr.) were also calculated in this case study.

\subsection{Precipitation Amounts, ETS, and Bias Score}

On the basis of the reasonable simulation in typhoon track and intensity (see section 4.2), the time series of averaged $3 \mathrm{~h}$ accumulated rainfall is compared in Fig. 9. The observed precipitation amounts, which are averaged for 391 rain gauge stations, present two rainfall episodes. One was late in the morning on 6 September (0603-0606 UTC) and the other was that midnight (0615-0618 UTC). For each simulation the rainfall was interpolated from the 3 $\mathrm{km}$ domain to all rain gauge locations in Taiwan using equations (1) and (2). In CTRL, there was agreement with the observations, except at the 0603-0612 UTC period where forecast rainfall was more than twice the observed. Moreover, the first episode produced more rain than the second but in the observations the two episodes had similar magnitudes. Such overforecasting during the early period and underforecasting during the late period of a simulation have been reported as a deficiency of rainfall simulations (Cai et al. 1992). Furthermore, owing to passage of the rainband, the observations shows rapidly decreasing rainfall during 0606-0612 but in CTRL the rainfall decreased more slowly and resulted in strongly overforecast precipitation. This rapid change in the observed precipitation amounts is still a big challenge for numerical weather prediction. For CLDS, the model precipitation was strongly affected by the spin-up problem during the initial 0-9 $\mathrm{h}$. Furthermore, the timing of the first rainfall peak was delayed about $3 \mathrm{~h}$ and the rainfall amounts were strongly underpredicted through the entire $24 \mathrm{~h}$ simulation. In NRAD case, which did not include Doppler radar data in the initial conditions, the simulated precipitation also presented two peak rainfall periods similar to CTRL. However, the precipitation was underforecast during the first $3 \mathrm{~h}$ simulation. This suggests that NRAD also needed about $3 \mathrm{~h}$ to spin-up the model rainfall and resulted in about a $3 \mathrm{~h}$ delay for the first simulated rainfall peak. Following the spin-up period, the simulated precipitation in NRAD increased quickly and became an overforecast during the 6-24 $\mathrm{h}$ period. Comparing the CTRL and NRAD reveals that the impact of Doppler radar data is evident on the early portion of rainfall simulation in our case study.

To examine the short-range precipitation forecasts of the LAPS/MM5 system, the ETS and bias score were computed at $6 \mathrm{~h}$ intervals and shown in Fig. 10. During the first $6 \mathrm{~h}$ simulation (0600-0606, Fig. 10a), the bias showed that the CTRL simulated rainfall was 


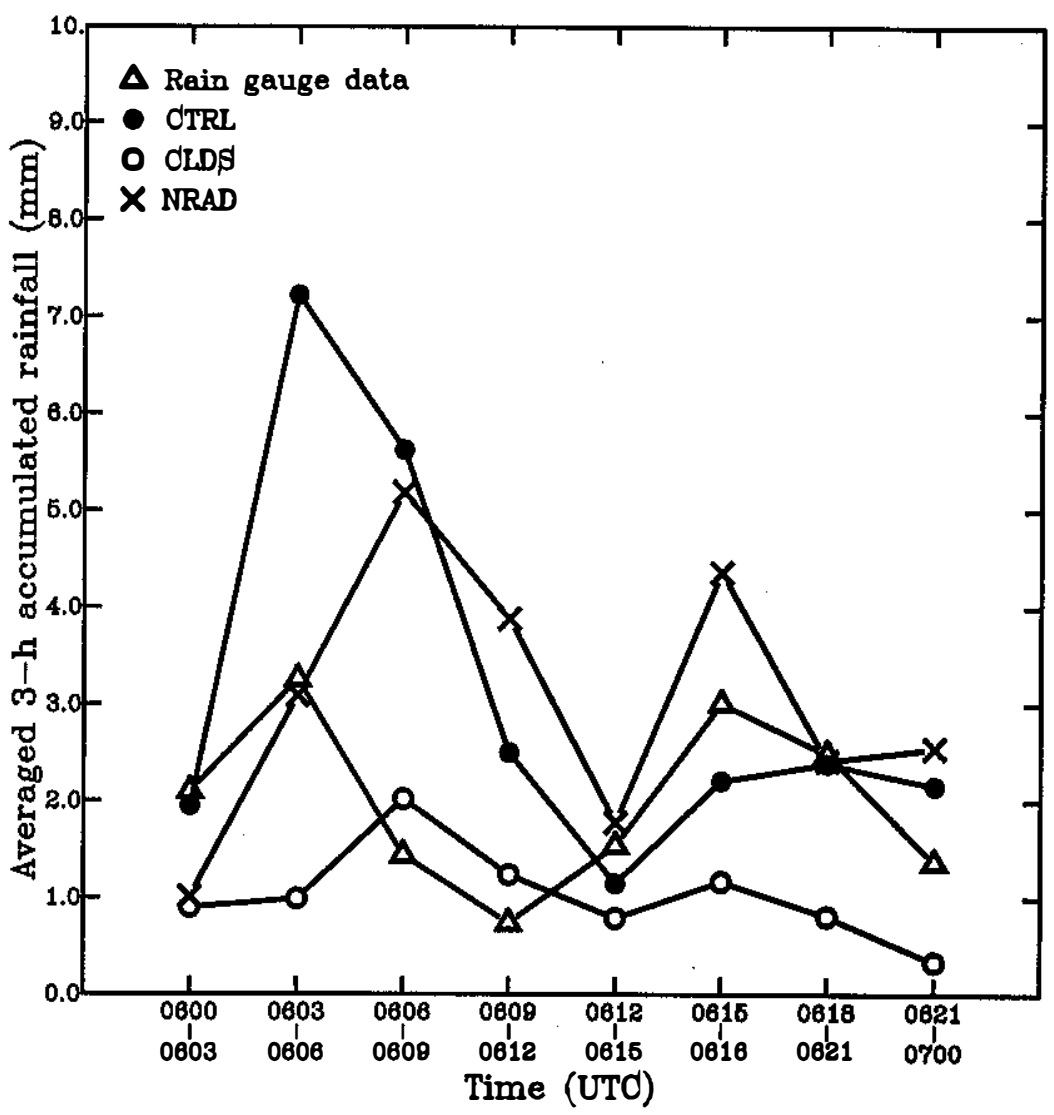

Fig. 9. Time series of $3 \mathrm{~h}$ accumulated precipitation averaged for the 391 precipitation verification samples in Taiwan from 0000 UTC 6 to 0000 UTC 7 September 2002.

overforecast, but had better ETSs than in CLDS for large thresholds ( $\geq 10 \mathrm{~mm}$ ). The highest ETS exceeded 0.35 at the $10 \mathrm{~mm}$ thresholds in this period. In contrast to CTRL, CLDS showed strong underforecasting. Although the ETSs of CLDS was comparable to CTRL at small thresholds, these ETSs dropped quickly as the threshold amounts increased. These results demonstrate that the LAPS/MM5 improves the forecasting of heavy rainfall during the early portion of integration. The large biases indicate that spin up is reduced, but the model appears to overshoot based on gauge observations. In NRAD, the precipitation was slightly overforecast at small thresholds and underforecast at large thresholds. The ETS scores show that NRAD performed better than CLDS but worse than CTRL at large thresholds ( $\geq 15 \mathrm{~mm}$ ). For small thresholds, the performance of NRAD was similar to CTRL. These results suggest that improvement in heavy rainfall simulation during 0-6 h was mostly due to including Doppler radar data in CTRL's initial conditions. To further investigate more details during this $6 \mathrm{~h}$ interval, we will show root-mean-square errors and correlation coefficients in the next 
subsection.

During the next $6 \mathrm{~h}$ interval (0606-0612), the observed rainfall amounts decreased rapidly, whereas the CLDS and NRAD produced more rain than the first $6 \mathrm{~h}$ period and the CTRL maintained precipitation longer than the observations (see Fig. 9). Therefore, all three experiments performed poorly, although the CLDS gave higher ETSs than the CTRL and NRAD at small thresholds (Fig. 10b). In this period, both CTRL and NRAD produced too much rain at all thresholds resulting in very high bias scores and low ETSs in Fig. 10b. Moreover, the CLDS also had similar high bias errors at thresholds larger than $15 \mathrm{~mm}$. These results reveal the limitations of a numerical model to capture the exact timing of the observed rainfall variation, especially for the early portion of the simulation. Missing the movement of the rainband was a large liability. During the next two $6 \mathrm{~h}$ intervals (0612-0618, Fig. 10c; 0618-0700, Fig. 10d), the CTRL and NRAD tended to underforecast the precipitation at small thresholds and overforecast at large thresholds. However, all precipitation was underforecast in CLDS. For ETSs, the CTRL and NRAD show a similar behavior and yield better scores than the CLDS for all thresholds during 12-24 h simulation.

In summary, comparing the simulated precipitation of CTRL, CLDS, and NRAD shows that the enhanced initial conditions with Doppler radar data yielded a positive impact on the early portion of precipitation simulation. Furthermore for Taiwan, the LAPS/MM5 system provided a better simulation than the non-LAPS cold start experiment for the precipitation associated with Typhoon Sinlaku. We feel these results are related to the LAPS diabatic initial conditions in the mesoscale model, which allows a better representation of the vertical motions, moisture field, and microphysical species, thus producing a better rainfall simulation and reducing the spin-up problem.

\subsection{Precipitation Distribution during 0-6 h Simulation}

The positive impact of the Doppler radar data on the early portion of precipitation simulation can be better discerned by comparing the precipitation distribution from all three experiments. Figure 11 shows forecast precipitation over Taiwan during 0600-0606 for CTRL, CLDS and NRAD. Comparing this figure to Fig. 4a, one notes that the CTRL simulation captures the areal distribution best among three experiments but did overforecast amounts. Figure 12 shows scatterplots comparing precipitation amounts from the rain gauge stations and the mesoscale model results. Moreover, the root-mean-square errors (RMSE) and correlation coefficients (Corr.) were calculated and are also shown in Fig. 12. In CTRL (Fig. 12a), the rainfall distribution between the observed amounts and the simulation reveals the evident overforecast at precipitation amounts less than $20 \mathrm{~mm}$. However, the CLDS (Fig. 12b) underforecast especially for precipitation amounts more than $30 \mathrm{~mm}$. The NRAD (Fig. 12c) produced more rainfall than the CLDS but still underforecast at large precipitation amounts. To examine the correlation between the observations and simulations, the correlation coefficients of CTRL, CLDS, and NRAD are $0.724,0.437$, and 0.443 , respectively illustrating the significantly better performance of the LAPS/MM5 system with assimilated Doppler radar data in this typhoon case study. Moreover, the similar correlation coefficient between CLDS and NRAD points out the critical role played by Doppler radar in the definition of cloud and 

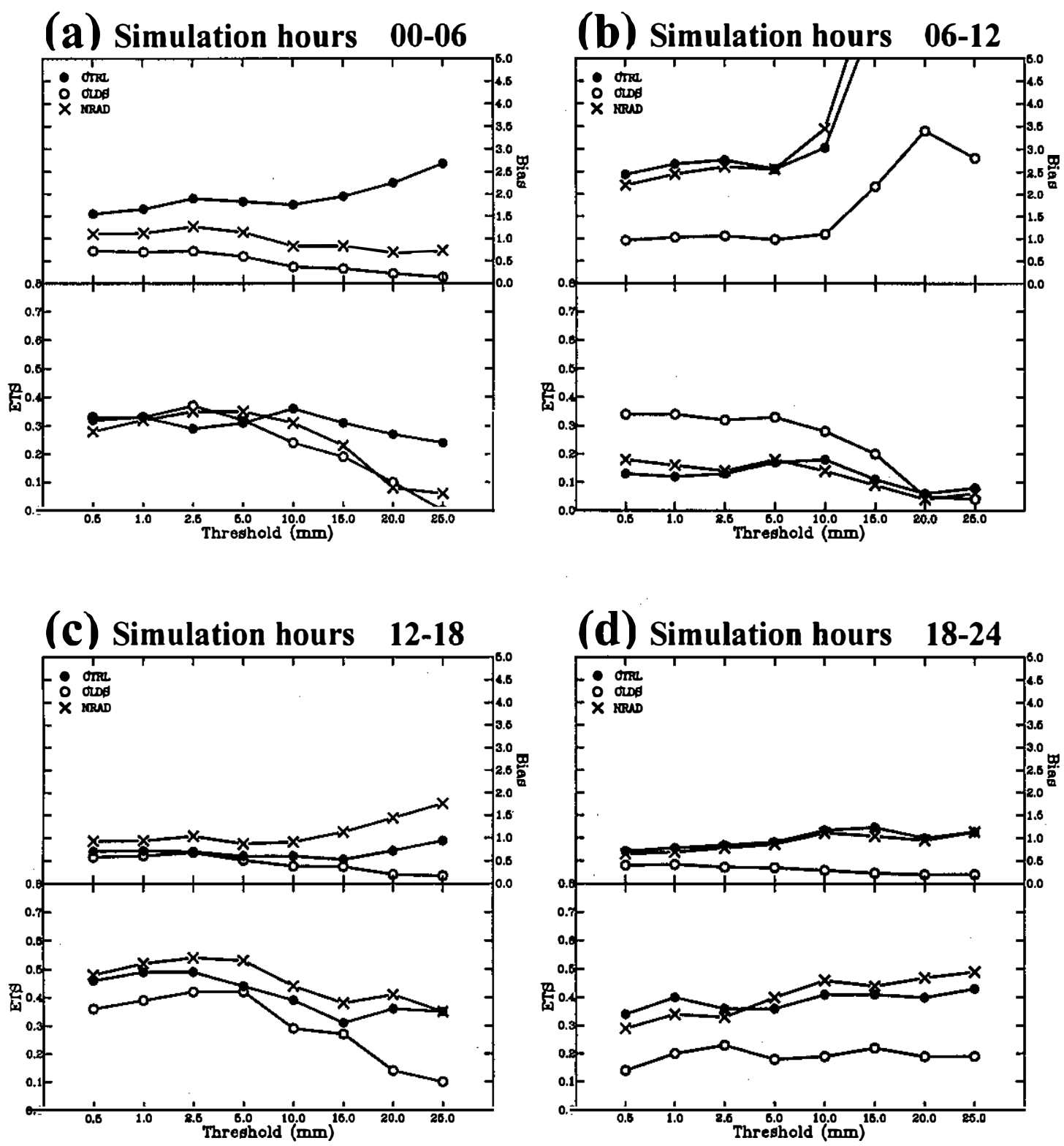

Fig. 10. Bias scores (upper panel) and equitable threat scores (ETS, lower panel) at various thresholds for (a) 0-6 hours, (b) 6-12 hours, (c) 12-18 hours, and (d) 18-24 hours accumulated precipitation simulation for the CTRL (filled circles), CLDS (open circles), and NRAD (cross signs). The bias magnitudes, which out of range for large thresholds in (b) are (6.2, 6.8, 6 . 6) for CTRL and $(6.4,7.2,6.9)$ for NRAD at the $(15 \mathrm{~mm}, 20 \mathrm{~mm}, 25$ $\mathrm{mm}$ ) precipitation thresholds. 

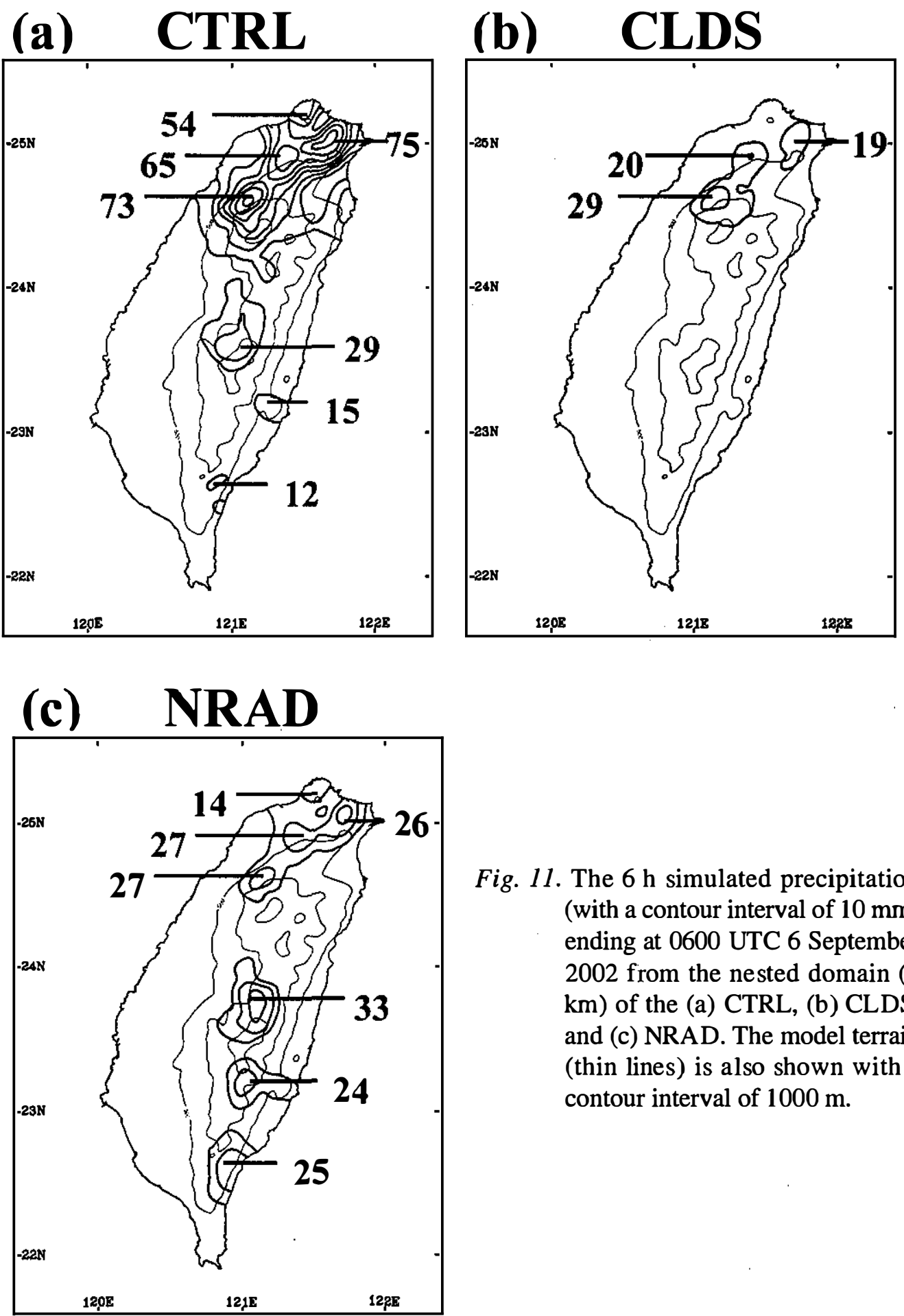

Fig. 11. The $6 \mathrm{~h}$ simulated precipitation (with a contour interval of $10 \mathrm{~mm}$ ) ending at 0600 UTC 6 September 2002 from the nested domain (3 $\mathrm{km}$ ) of the (a) CTRL, (b) CLDS, and (c) NRAD. The model terrain (thin lines) is also shown with a contour interval of $1000 \mathrm{~m}$. 

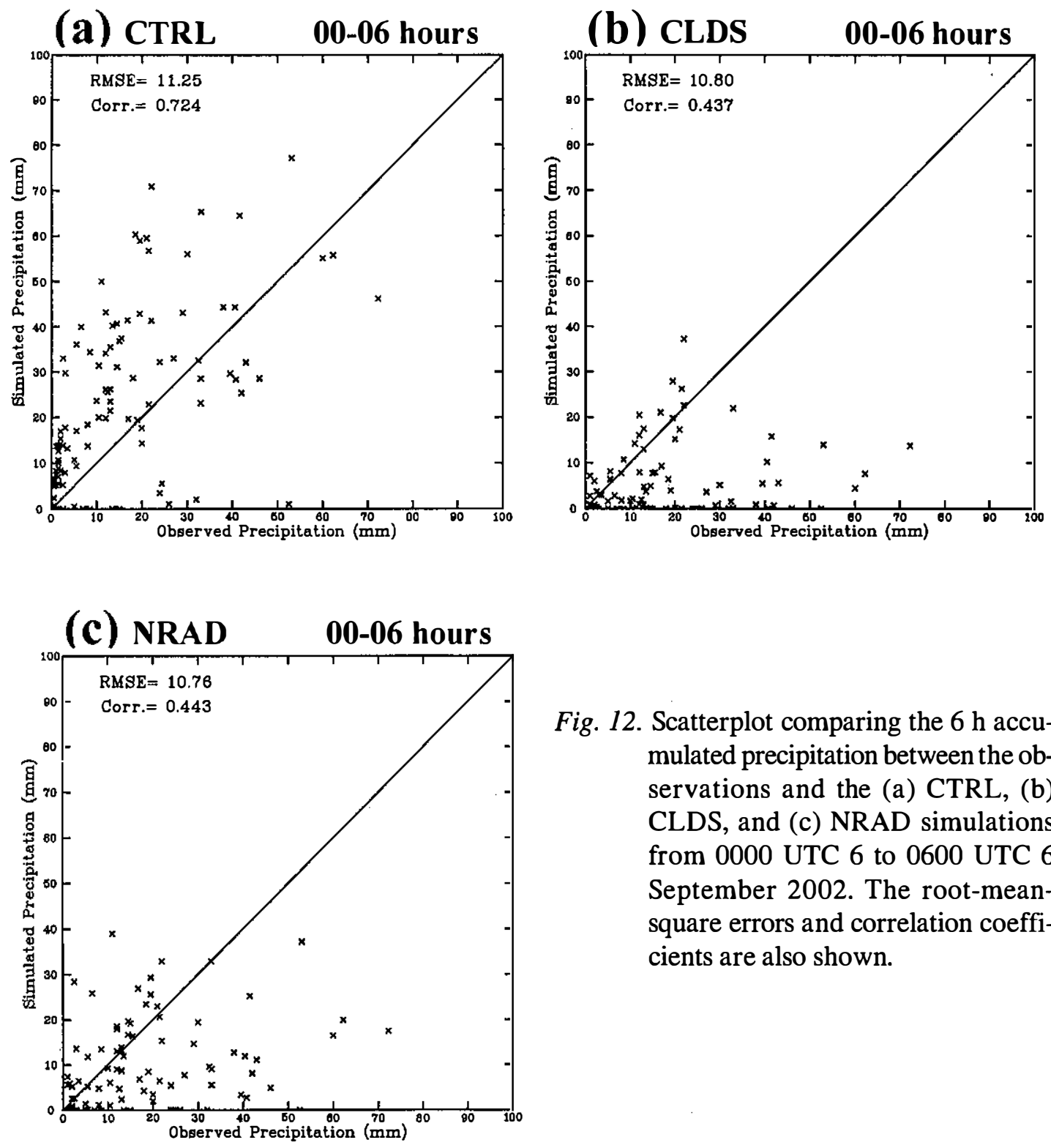

Fig. 12. Scatterplot comparing the $6 \mathrm{~h}$ accumulated precipitation between the observations and the (a) CTRL, (b) CLDS, and (c) NRAD simulations from 0000 UTC 6 to 0600 UTC 6 September 2002. The root-meansquare errors and correlation coefficients are also shown.

estimation of cloud variables. Inclusion of radar in the initial conditions of CTRL allowed improvement in the skill at higher precipitation, where CLDS and NRAD showed deficiencies (see Fig. 10a). As to the RMSE, all three simulations show comparable values with $11.25 \mathrm{~mm}$, $10.80 \mathrm{~mm}$, and $10.76 \mathrm{~mm}$ for CTRL, CLDS, and NRAD, respectively. In summary, the simulated precipitation distributions associated with Typhoon Sinlaku suggest that the Wu-FenShan Doppler radar data played a key role in enhancing the heavy rainfall prediction ability for the LAPS/MM5 system during the early portion of the simulation. However, there was no evident improvement for light rain prediction. 


\section{DISCUSSION AND CONCLUSION}

Two objectives of this paper were to evaluate the performance of the precipitation simulation associated with Typhoon Sinlaku from MM5 model initialized diabatically with the high-resolution ( $9 \mathrm{~km}$ horizontal grid interval) operational LAPS data assimilation system and determine the impact of the Wu-Fen-Shan Doppler radar data on the simulation results. All experiments were performed over $24 \mathrm{~h}$ and begun at 0000 UTC 6 September 2002. During the period when Typhoon Sinlaku passed to the sea north of Taiwan, observed rainfall analysis from 391 rain gauge stations showed that the precipitation associated with typhoon over Taiwan was, in general, phase-locked with the northern Central Mountain Range and mostly confined to 6 September with two major rainfall episodes. One was late in the morning (06030606 UTC) and the other near midnight (0615-0618 UTC). The major emphasis of this study is to evaluate the simulated precipitation from the LAPS/MM5 system during the first rainfall episode since it was in the early portion (0-6 h) of model integration.

In this typhoon case study, precipitation simulation from the LAPS/MM5 system showed some improvement over conventional initialization methods used at the CWB. Comparison with precipitation simulation from the non-LAPS cold start experiment shows that the MM5 initialized diabatically with LAPS has higher skill for precipitation associated with Sinlaku over Taiwan, especially for the heavy rainfall in the early portion of the simulation ( $\geq 10 \mathrm{~mm}$ in 0-6 h). For the $25 \mathrm{~mm}$ precipitation threshold, the equitable threat score (ETS) in 0-6 h simulation was about 0.24 for LAPS/MM5 case but only about 0.01 for non-LAPS cold start experiment. Furthermore, the initial conditions provided by the LAPS/MM5 system captured many important typhoon cloud features from satellite and Doppler radar data. We surmise that the initial hydrometeor species from LAPS cloud analysis allows the LAPS/MM5 system to present better the microphysics fields and thus benefit typhoon heavy rainfall forecasts by reducing the model spin-up time during the early portion of the simulation. For light rainfall, however, the LAPS/MM5 had no evident improvement in our case study since the light precipitation was strongly overforecast.

Effects of the Wu-Fen-Shan Doppler radar on model simulation were reflected in two aspects of model results. First, the improvement of heavy rainfall simulation during the $0-6 \mathrm{~h}$ integration was mainly due to the use of radar data. Second, simulations of the typhoon rainbands, especially the outer rainband which located near the northern Taiwan coast, were also enhanced when Doppler radar data were included in the LAPS data assimilation procedures. However, the radar data in this case study had no significant influence on the typhoon track and the evolution of minimum sea-level pressure. Differences in the simulation of Typhoon Sinlaku with and without Doppler radar data also show that the simulation without radar data still needed about $3 \mathrm{~h}$ to spin-up model precipitation and the typhoon winds near surface were stronger when the radar data was included. This indicates that Doppler radar data play a positive impact role on resolving the three dimensional cloud fields to provide a good diabatic initial condition.

In this study, the simulation results suggest that the LAPS diabatic initialization has a positive impact on short-range typhoon heavy rainfall prediction. Since one case study may not be sufficient to judge the overall effectiveness of the LAPS scheme, attempts are ongoing 
to apply this LAPS/MM5 system to other typhoon cases, such as Typhoon Rammasun (2002), which was designated a tropical storm at 0600 UTC 29 June 2002 and a typhoon at 1800 UTC 1 July. Similar to Sinlakı, Typhoon Rammasun produced moderate rainfall, and the precipitation distribution indicated a orographically locked feature over northern Taiwan when it was passing through the sea northeast of Taiwan. It is also acknowledged the present study is only one case, and we do not claim the spin-up problem has been solved by this diabatic data assimilation technique. In addition, the coverage of the $\mathrm{Wu}$-Fen-Shan Doppler radar is localized in the southwest side of the Typhoon Sinlaku. The impact of such localized and asymmetric wind data, in particular, for more longer time-scale simulation is needed to investigate further. However, our results show the potential capability for short-range quantitative precipitation forecasts (QPF) and severe weather (e.g., tropical cyclone) forecasts. Especially, with the use of four Doppler radar network data over Taiwan area in the future, the advantages of the LAPS/MM5 system may be more fully realized. Furthermore, improving the LAPS dynamic balance scheme by adding thermodynamic terms to the cost function equation such that anomalous clouds in the first guess field can be properly removed based on the LAPS cloud analysis is still in progress to enhance the advantage of precipitation prediction.

Acknowledgements The present research was supported by the Climate Variation, Severe Weather Monitoring, and Forecasting System Development Project at the Central Weather Bureau. The authors are grateful to Junichi Tsutsui, senior researcher, Central Research Institute of Electric Power Industry, Japan and one anonymous reviewer for the insightful comments that substantially improved the original manuscript.

\section{REFERENCES}

Albers, S., 1995: The LAPS wind analysis. Wea. Forecasting, 10, 342-352.

Albers, S., J. McGinley, D. Birkenheuer, and J. Smart, 1996: The Local Analysis and Prediction System(LAPS): Analyses of clouds, precipitation, and temperature. Wea. Forecasting, 11, 273-287.

Bames, S. L., 1964: A technique for maximizing details in numerical weather map analysis. J. Appl. Meteor., 3, 396-409.

Bender, M. A., R. E. Tuleya, and Y. Kurihara, 1987: A numerical study of the effect of island terrain on tropical cyclones. Mon. Wea. Rev., 115, 130-155.

Birkenheuer, D., 2001: Utilizing variational methods to incorporate a variety of satellite data in LAPS moisture analysis. $11^{\text {th }}$ Conf. on Satellite Meteorology and Oceanography, Madison, WI, Amer. Meteor. Soc., 273-276.

Brand, S., and J. W. Blelloch, 1974: Changes in the characteristics of typhoons crossing the island of Taiwan. Mon. Wea. Rev., 102, 708-713.

Businger, S., D. I. Knapp, and G. F. Watson, 1990: Storm following climatology of precipitation associated with winter cyclones originating over the Gulf of Mexico. Wea. Forecasting, 5, 378-403.

Cai, Z. Y., Z. S. Wang, and Z. T. Pan, 1992: A numerical study on forecasting the Henan extraordinary heavy rainfall event in August 1975. Adv. Atmos. Sci., 9, 53-62. 
Chang, S. W., 1982: The orographic effects induced by an island mountain range on propagating tropical cyclones. Mon. Wea. Rev., 110, 1255-1270.

Chang, S. W., and T. R. Holt, 1994: Impact of assimilation SSM/I rainfall rates on numerical prediction of winter cyclones. Mon. Wea. Rev., 122, 151-164.

Cressman, G., 1959: An operational objective analysis system. Mon. Wea. Rev., 87, 367-374.

Colle, B. A., K. J. Westrick, and C. F. Mass, 1999: Evaluation of MM5 and Eta-10 precipitation forecasts over the Pacific Northwest during the cool season. Wea. Forecasting, 14, 137-154.

Davidson, N. E., and K. Puri, 1992: Tropical prediction using dynamical nudging, satellitedefined convective heat sources, and a cyclone bogus. Mon. Wea. Rev., 120, 25012522.

Davis, C. A., and S. Low-Nam, 2001: The NCAR-AFWA tropical cyclone bogussing scheme. NCAR Technical Note, 13pp. Available from http://www.mmm.ucar.edu/mm5/mm5v3/ tc-report.pdf.

Donner, L. J., 1988: An initialization for cumulus convection in numerical weather prediction models. Mon. Wea. Rev., 116, 377-385.

Haines, P. A., J. K. Luers, and C. A. Cerbus, 1989: The role of the Smith-Feddes model in improving the forecasting of aircraft icing. $3^{\text {rd }}$ Conf. on Aviation Weather System, Anaheim, Cal, Amer. Meteor. Soc., 258-263.

Heckley, W. A., 1985: Systematic errors of the ECMWF operational forecasting model in tropical regions. Quart. J. Roy. Meteor. Soc., 111, 709-738.

Hong, S. Y., and H. L. Pan, 1996: Nonlocal boundary layer vertical diffusion in a mediumrange forecast model. Mon. Wea. Rev., 124, 2322-2339.

Karyampudi, V. M., G. S. Lai, and J. Manobianco, 1998: Impact of initial conditions, rainfall assimilation, and cumulus parameterization on simulations of Hurricane Florence (1988). Mon. Wea. Rev., 126, 3077-3101.

Klemp, J. B., and D. R. Durran, 1983: An upper boundary condition permitting internal gravity wave radiation in numerical mesoscale models. Mon. Wea. Rev., 111, 430-444.

Lewis, J. M., 1971: Variational subsynoptic analysis with applications to severe local storms. Mon. Wea. Rev., 99, 786-795.

Lin, Y. L., J. Han, D. W. Hamilton, and C. Y. Huang, 1999: Orographic influence on a drifting cyclone. J. Atmos. Sci., 56, 534-562.

McGinley, J. A., S. Albers, and P. Stamus, 1991: Validation of a composite convective index as defined by a real-time local analysis system. Wea. Forecasting, 6, 337-356.

McGinley, J. A., and J. R. Smart, 2001: On providing a cloud-balanced initial condition for diabatic initialization. $14^{\text {th }}$ Conf. on Numerical Weather Prediction, Ft. Lauderdale, Amer. Meteor. Soc., 40-44.

Mlawer, E. J., S. J. Taubman, P. D. Brown, M. J. Iacono, and S. A. Clough, 1997: Radiative transfer for inhomogeneous atmosphere: RRTM, a validated correlated-k model for the longwave. J. Geophys. Res., 102(D14), 16663-16682.

Molinari, J., 1982: Numerical hurricane prediction using assimilation of remotely-sensed rainfall rates. Mon. Wea. Rev., 110, 553-571.

Olson, D. A., N. W. Junker, and B. Korty, 1995: Evaluation of 33 years of quantitative pre- 
cipitation forecasting at the NMC. Wea. Forecasting, 10, 498-511.

Schaefer, J.T., 1990: The critical success index as indicator of waming skill. Wea. Forecasting, 5, 570-575.

Schultz, P., 1995: An explicit cloud physics parameterization for operational numerical weather prediction. Mon. Wea. Rev., 123, 3331-3343.

Schultz, P., and S. Albers, 2001: The use of three-dimensional analyses of cloud atributes for diabatic initialization of mesoscale models. $14^{\text {th }}$ Conf. on Numerical Weather Prediction, Ft. Lauderdale, Amer. Meteor. Soc., J122-J124.

Shaw, B. L., E. R. Thaler, and E. J. Szoke, 2001: Operational evaluation of the LAPS-MM5 ìhot startî local forecast model. $18^{\text {th }}$ Conf. on Wea. Anal. and Forecasting, Ft. Lauderdale, Amer. Meteor. Soc., 160-164.

Shi, J. J., S. Chang, and S. Raman, 1996: Impact of assimilation of dropwindsonde data and SSM/I rain rates on numerical prediction of Hurricane Florence (1988). Mon. Wea. Rev., 124, 1435-1448.

Shieh, S. L., S. T. Wang, M. D. Cheng, and T. C. Yeh, 1997: User's guide for typhoon forecasting in the Taiwan area (in Chinese). Central Weather Bureau Research Rep. CWB851M-01, 381pp.

Snook, J., J. M. Cram, and J. Schmidt, 1996: LAPS/RAMS, 1995: A nonhydrostatic mesoscale numerical modeling system configured for operational use. Tellus, 47A, 864-875.

Wang, S. T., 1980: Prediction of the behavior and strength of typhoons in Taiwan and its vicinity. Res. Rep. 108, National Science Council, Taipei, Taiwan, 100pp.

Wu, C.-C., and Y. H. Kuo, 1999: Typhoons affecting Taiwan: Current understanding and future challenges. Bull. Amer. Meteor. Soc., 80, 67-80.

Wu, C.-C., 2001: Numerical simulation of Typhoon Gladys (1994) and its interaction with Taiwan terrain using the GFDL hurricane model. Mon. Wea. Rev., 129, 1533-1549.

Yeh, T. C., and R. L. Elsberry, 1993a: Interaction of typhoons with the Taiwan orography. Part I: Upstream track deflections. Mon. Wea. Rev., 121, 3193-3212.

Yeh, T. C., and R. L. Elsberry, 1993b: Interaction of typhoons with the Taiwan orography. Part II: Continuous and discontinuous tracks across the island. Mon. Wea. Rev., 121, 3213-3233. 